\title{
Benzothiazole Derivative Accelerates Excretion of Total Sterols in Long-Term High Fat Fed C57BL/6J Mice
}

\author{
Yue Yu, Heng Jiang, Junli Ao, Hao Wang, Erbing Hua \\ Key Laboratory of Industrial Microbiology, College of Biotechnology \\ Tianjin University of Science \& Technology \\ Tianjin, China \\ e-mail:13821524700@163.com
}

\begin{abstract}
Benzothiazole derivative (BD): [N-(3-(benzothiazol2-yl) phenyl)-1H-pyrazole-3-carboxamide] was tested for excretion of total sterols of high-fat diet fed C57BL/6J mice in view of lipid metabolism. The results showed that $\mathrm{BD}$ as supplementation of high-fat diet significantly improved the output of cholesterol in comparison to HF alone. Relevant mRNA expressions of HMG-CoA-R, SREBP-2, LDL-R, CYP7A1 and PPARa were significantly altered in liver. These results suggest that $\mathrm{BD}$ could promote the excretion of total sterols and play a beneficial role in lipids metabolism for a high-fat fed mice.
\end{abstract}

Keywords-excretion; total sterols; mRNA regulation; benzothiazole derivative

\section{INTRODUCTION}

Hyperlipidemia is a dominant risk factor that contributes to the development and progression of atherosclerosis and subsequent cardiovascular disease, which is one of the most serious diseases for humans [1-4]. The BD has proved to improve the plasma and hepatic lipid profile and blood glucose through upregulating SIRT1, FOXO1, PPAR $\gamma$ and PGC-1 $\alpha$ genes [5].

Inhibitors (statins) of HMG-CoA-R have been used to inhibit cholesterol synthesis [6]. SREBP-2 is mainly involved in regulating cholesterol biosynthesis [7]. LDL-R draws cholesterol out of the circulation to lower plasma cholesterol levels [8]. Cholesterol 7- $\alpha$-hydroxylase (CYP7A1) is the rate-limiting enzyme in the synthesis of bile acid in the liver via the 'classic' pathway, producing 7- $\alpha$ hydroxycholesterol [9]. PPAR $\alpha$ is a transcription factor that has been shown to up-regulate for the fatty acid beta oxidation mainly in the liver and heart [10]. Therefore, the current study on effect of BD on excretion of total sterols was made via regulation of relevant genes such as PPAR $\alpha$, HMG-CoA-R, CYP7A1, LDL-R, and SREBP-2. The experimental results would answer how BD could impact excretion of total sterols of fat-fed mice in view of relevant genetic regulations.

\section{Materials AND Methods}

A. Synthesis and the characterization of BD (Fig 1) refer to the paper [5].

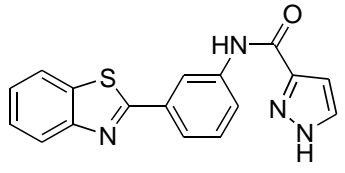

Figure 1. Structure of BD

\section{B. Animals and diets}

Male C57BL/6J mice were purchased from Vital River Laboratories (Beijing, China) and maintained under a light cycle (12 h light/dark), temperature $\left(21 \sim 23^{\circ} \mathrm{C}\right)$ and humidity (40 60\%) conditions. The mice were divided randomly into three groups $(n=10)$. Thereafter, the control group was fed a standard diet and the experimental group of the mice was fed a diet that contains more sucrose and more solid lard (Table 1). All experimental procedures were in accordance with the institutional guidelines for animal research. Feces were collected and subsequently lyophilized during the last $72 \mathrm{~h}$ of the experimental period. At the end of the experimental period of 12 weeks. the mice were anesthetized with ethyl ether and liver was quickly dissected out, immediately frozen in liquid nitrogen, and stored at $-80{ }^{\circ} \mathrm{C}$ until RNA analysis later.

\section{Analysis of fecal sterols}

Feces were collected during the last $72 \mathrm{~h}$ of the experimental period. Fecal lipids were analyzed by GLC according to Batta et al. [11]. In brief, $75 \mathrm{mg}$ of lyophilized feces were butylated by addition of $1 \mathrm{ml} \mathrm{n}$-butylalcohol and $0.1 \mathrm{ml} 6 \mathrm{~N} \mathrm{HCl}$. Nor cholic acid and $5 \alpha$-cholestane were added as internal.

TABLE I. COMPositions of the EXPERIMENTAl Diets (\%)

\begin{tabular}{llll}
\hline Component & Control group & High-fat group & BD \\
\hline Casein & 20 & 20 & 20 \\
DL-methionine & 0.3 & 0.3 & 0.3 \\
Sucrose & 20 & 35 & 35 \\
Corn starch & 41.7 & 11.4 & 11.3 \\
Lard & 5 & 20 & 20 \\
Cholesterol & - & 0.3 & 0.3 \\
Cellulose & 5 & 5 & 5 \\
Mineral mix & 4 & 4 & 4 \\
Vitamine mix & 2 & 2 & 2 \\
Gelatin & 2 & 2 & 2 \\
BD & - & - & 0.1 \\
Total & 100 & 100 & 100 \\
\hline
\end{tabular}


TABle II. List of Oligonucleotide Primers Used to Amplify mRNA by ReAl-Time PCR

\begin{tabular}{lll}
\hline Gene & Accession number & primer \\
\hline \multirow{2}{*}{ GAPDH } & NM_008084.2 & F: 5'-ATGCTGGCGCCGAGTATGTTG-3' \\
HMG-CoA- & NM_068255.2 & R:5'-CAGAAGGTGCGGAGATGATGAC -3' \\
R & & F: 5'-CCAATGGCAACAACGGAAGG-3' \\
SREBP-2 & NM_033218.1 & R:5'-GAATCACAAGCACGAGGAAGAC-3' \\
& & F: 5'-GCAGCAGGTCAATCACAAG-3' \\
LDL-R & NM_001252658.1 & R: 5'-GGCGGAGACATCAGAAGC -3' \\
& NM_007824.2 & F: 5'-CGCTGGTGACTGAGGACATC -3' \\
CYP7A1 & R: 5'-ATCAATGCTGGAGATAGAGTGGAG -3' \\
& NM_003513416.1 & F: 5'-CTAAGCACAGACTCTCCTCTTGG -3' \\
PPAR $\alpha$ & & R: 5'-CAACAGCACACTACCATAGCAATC-3' \\
& & F: 5'-CAATGCTGTCCTCCTTGATGAAC -3' \\
\end{tabular}

Table III. Effect of BD on Fecal Output of Neutral \& Acidic Sterols in C57BL/6J Mice

\begin{tabular}{|c|c|c|c|}
\hline Sterols & $\mathrm{HF}+\mathrm{BD}$ & HF & Control \\
\hline Coprostanol (mg/g) & $5.33 \pm 0.21$ & $4.91 \pm 0.04$ & $1.63 \pm 0.11 * *$ \\
\hline Coprostanone(mg/g) & $1.74 \pm 0.37 *$ & $1.84 \pm 0.16$ & $0.99 \pm 0.13$ \\
\hline Cholesterol(mg/g) & $15.01 \pm 2.52$ & $11.57 \pm 0.30$ & $6.42 \pm 1.45^{*}$ \\
\hline Dihydrocholesterol & $0.36 \pm 0.02$ & $0.70 \pm 0.01$ & $0.58 \pm 0.14^{*}$ \\
\hline Campersterol(mg/g) & $0.52 \pm 0.05$ & $0.76 \pm 0.19$ & $0.42 \pm 0.05^{*}$ \\
\hline Total neutral sterols $(\mathrm{mg} / \mathrm{g})$ & $22.96 \pm 2.61$ & $19.78 \pm 0.96$ & $10.05 \pm 3.75^{*}$ \\
\hline Lithocholic acid (mg/g) & $1.37 \pm 0.08^{*}$ & $1.21 \pm 0.14$ & $0.90 \pm 0.21$ \\
\hline Deoxycholic acid(mg/g) & $0.45 \pm 0.01$ & $0.58 \pm 0.07$ & $0.23 \pm 0.04 *$ \\
\hline Chenodeoxycholic acid (mg/g) & $0.53 \pm 0.12 *$ & $0.34 \pm 0.02$ & $0.15 \pm 0.05 *$ \\
\hline Cholic acid (mg/g) & $1.26 \pm 0.02$ & $0.76 \pm 0.17$ & $0.32 \pm 0.08$ \\
\hline Ursodexoycholic acid (mg/g) & $0.23 \pm 0.01$ & $0.17 \pm 0.01$ & $0.07 \pm 0.02 *$ \\
\hline Total acidic sterols $(\mathrm{mg} / \mathrm{g})$ & $3.84 \pm 1.02$ & $3.06 \pm 0.69$ & $1.67 \pm 0.35 *$ \\
\hline
\end{tabular}

standards. The mixture was incubated for $4 \mathrm{~h}$ at $60^{\circ} \mathrm{C}$ and thereafter the solvents evaporated at $60^{\circ} \mathrm{C}$ under air stream. Samples were silylated with $1 \mathrm{ml}$ Sil-Prep kit (Alltech, USA) at $55^{\circ} \mathrm{C}$ for $30 \mathrm{~min}$ and thereafter resuspended in $1 \mathrm{ml}$ hexane, centrifuged, and supernatant were transferred to new vials and brought to a final volume of $50 \mu \mathrm{l}$. A sample of $1 \mu \mathrm{l}$ was applied to an SGE $30 \mathrm{~m} \times 0.25 \mathrm{~mm} \times 0.25 \mathrm{~lm}$ capillary GLC column. The results were analyzed with a Clarity program (Data Apex Ltd., Czech Republic).

\section{Real-time quantitative polymerase chain reaction}

Total RNA was extracted from the tissue of individual animals, and reverse transcripted as described [12] and gene expression levels were measured by real-time quantitative PCR using the BIO-RAD IQ-Cycler. Levels of mRNA were normalized to GAPDH mRNA levels. The primers utilized for GAPDH, HMG-CoA, SREBP-2, LDL, CYP7A1 and PPAR $\alpha$ and are listed in Table II.

\section{RESULtS}

A. Fecal sterols and bile acids
The total fecal sterol output — neutral and acidic sterols levels of all groups were investigated and shown in Table 3.

\section{B. Real-time PCR analysis}

To investigate the effect of oral administration of $\mathrm{BD}$ on the hepatic gene expression correlated with cholesterol homoeostases, five major proteins and enzymes, HMG-CoAR, SREBP-2, LDL-R, CYP7A1 and PPAR $\alpha$ were considered by real-time PCR analysis (Fig. 3). The result showed that BD could remarkably decrease the HMG-CoA-R $(\mathrm{p}<0.01)$ and SREBP-2 gene expression, whereas increased the CYP7A1 $(p<0.01)$, LDL-R and PPAR $\alpha$ gene expression.

\section{Discussion}

Our study showed that BD down-regulated HMG-CoA reductase, whereas $\mathrm{BD}$ had no effect on SREBP-2 expression at mRNA levels. In addition, BD up-regulated the CYP7A1, PPAR $\alpha$ and LDL-R mRNA expression in a different degree. As a result, BD promoted the more output of faecal cholesterol and total bile acids concentrations than that of high-fat group alone via regulation of relevant genes by BD. 
(a)

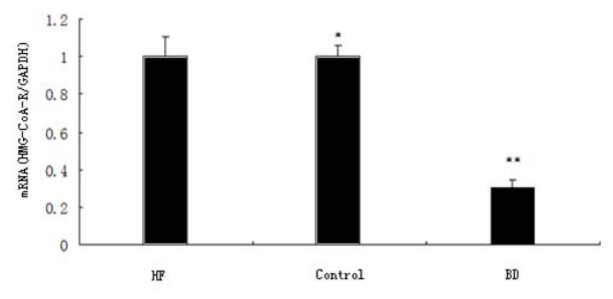

(c)

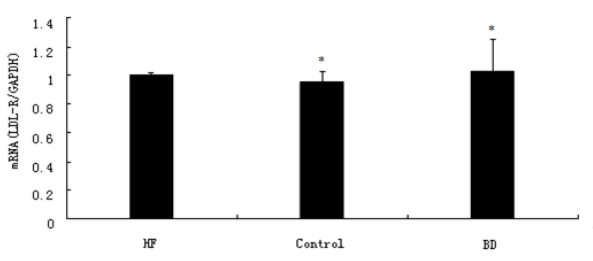

(b)

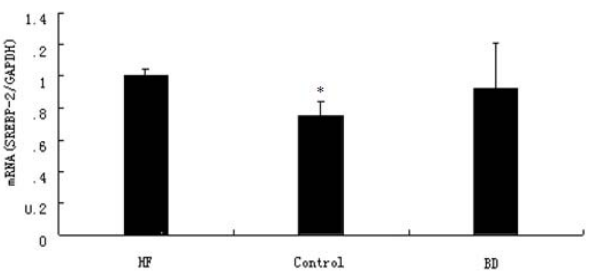

(d)

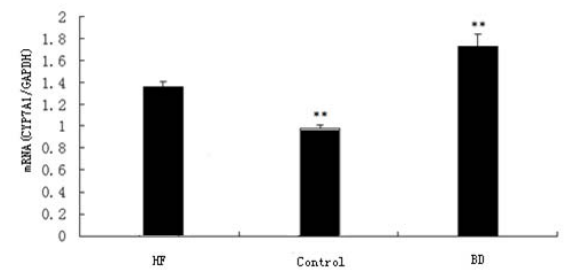

(e)

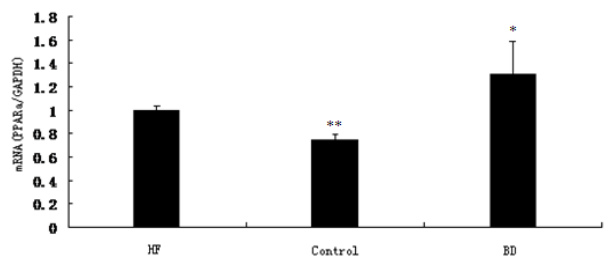

Figure 2. $\quad$ Relative mRNA expressions of hepatic HMG-CoA-R(a), SREBP-2(b), LDL-R(c), CYP7A1(d) and PPAR $\alpha(e)$ by real time PCR analysis. Mean $\pm \mathrm{SD}, \mathrm{n}=10$, mRNA was normalized to GAPDH and expressed as a ratio to the corresponding amount in the HF group. $*$ designates statistically significant difference with HF group $(\mathrm{p}<0.05)$, **designates statistically significant difference with HF group $(\mathrm{p}<0.01)$.

\section{ABBreviations}

$\operatorname{PPAR} \alpha$ (peroxisome proliferator-activated receptor alpha); HMG-CoA-R (3-hydroxy-3-methylglutarylcoenzyme A reductase); CYP7A1(cholesterol-7 $\alpha-$ hydroxylase); LDL-R (low density lipoprotein receptor) and SREBP-2 (sterol regulatory element binding protein-2); GAPDH (glyceraldehyde 3-phosphate dehydrogenase) .

\section{ACKNOWLEDGMENT}

This work was supported by grants from the National Natural Science Foundation of China (grant no. 81072521) and Tianjin University of Science \& Technology (grant no. 20100411).

\section{REFERENCES}

[1] K. Prasad, and J. Kalra, "Oxygen free radicals and hypercholesterolemic atherosclerosis: effect of vitamin E," American
Heart Journal,vol.125,Apr.1993,pp.958-973， doi:10.1016/00028703(93)90102-F.

[2] P. R. Deepa, and P. Varalakshmi, "Atheroprotective effect of exogenous heparin-derivative treatment on the aortic disturbances and lipoprotein oxidation in hypercholesterolemic diet fed rats," Clinica Chimica Acta, vol.355,Jan.2005,pp.119-130, doi:10.1016/j.ccen.2004.12.007.

[3] W. S. He, , C. S. Jia, and Y. B. Yang, "Cholesterol-lowering effects of plant steryl and stanyl laurate by oral administration in mice," Journal of Agricultural \& Food Chemistry,vol.59,sept.2011,pp.5093-5099.doi: 10.1016/j.virol. 2004.10.004.

[4] E. D. Smet, R. P. Mensink, and J. Plat, "Effects of plant sterols and stanols on intestinal cholesterol metabolism: Suggested mechanisms from past to present," Molecular Nutrition \& Food Research,vol.56, Jul.2012,pp.1058-1072,doi: 10.1002/mnfr.201100722.

[5] Q. Gu, et al., "Benzothiazole derivatives upregulate SIRT1 and relevant genes in high-fat fed C57BL/6J mice," Medicinal Chemistry Research,vol.24,Jun.2014,pp.1-7,doi: 10.1007/s00044-014-1307-3.

[6] Group, Scandinavian Simvastatin Survival Study, "Randomised trial of cholesterol lowering in 4444 patients with coronary heart disease: the Scandinavian Simvastatin Survival Study (4S). 1994," Atherosclerosis 
Supplements, vol.5,May.2004, pp:81-87,doi: $\quad 10.1016 / \mathrm{j}$. atherosclerosissup.2004.08.027.

[7] M. S. Brown, and J. L. Goldstein, "The SREBP Pathway: Regulation of Cholesterol Metabolism by Proteolysis of a Membrane-Bound Transcription Factor," Cell, vol.89,Mar.1997,pp.331-340,doi: 10.1016/S0092-8674(00)80213-5.

[8] P. T. Ma, et al., "Mevinolin, an inhibitor of cholesterol synthesis, induces mRNA for low density lipoprotein receptor in livers of hamsters and rabbits," Proceedings of the National Academy of Sciences of the United States of America,vol.83,Nov.1986,pp.83708374,doi: 10.1073/pnas.83. 21.8370.

[9] J.Y.L. Chiang, "Bile acids: regulation of synthesis," Journal of Lipid Research,vol.50,Oct.2009,pp.1955-1966,doi: 10.1194/jlr. R900010JLR200.
[10] S. W.Beaven and P. Tontonoz, "Nuclear receptors in lipid metabolism: targeting the heart of dyslipidemia," Annual Review of Medicine,vol.57, Feb.2006, pp.313-329, doi: 10.1146/annurev .med. 57. 121304.131428.

[11] A.K .Batta, et al., "Simultaneous quantitation of fatty acids, sterols and bile acids in human stool by capillary gas-liquid chromatography," Journal of Chromatography B vol.775,Feb.2002,pp. 153-161,doi: 10.1016/S1570-0232(02)00289-1.

[12]N. H. Kim, et al., "Green tea seed oil reduces weight gain in C57BL/6 J mice and influences adipocyte differentiation by suppressing peroxisome proliferator-activated receptorgamma," Pflügers Archiv European Journal of Physiology, vol.457, Feb.2008, pp.293-302, doi: 10.1007/s00424-0080537-y. 